\title{
Weather parameter based crop planning in Tarai region of Uttarakhand
}

VIVEKANAND, VINOD KUMAR, VIJAY KUMAR SINGH AND BHASKAR PRATAP SINGH

Received : 24.04.2017; Revised : 29.07.2017; Accepted : 13.08.2017

See end of the Paper for authors' affiliation

Correspondence to :

VIJAY KUMAR SINGH

Department of Soil and Water Conservation Engineering,

G.B. Pant University of

Agriculture and Technology,

Pantnagar, U.S. NAGAR (UTTARAKHAND) INDIA

Email:vijaysinghswce

@gmail.com
-ABSTRACT : The major weather parameters like temperature, relative humidity, rainfall, wind speed and sunshine hour for a period of 43 years were collected and analyzed. This was done for crop planning and to develop an appropriate irrigation scheduling for different crops. The annual rainfall record indicated that in 40.47 per cent cases the normal rainfall (average $\pm 19 \%$ ) was received in the study area, whereas, the per cent of below normal and above normal rainfall was found as 33.33 and 26.20 per cent, respectively. The highest PET was obtained in April and the lowest in December. The maximum net irrigation requirements for Rabi and Kharif season crops were found in February, March, April, June, September, October and November months. June to September months received the highest rainfall when the rainfall was received about 86 per cent of the total amount of annual rainfall. It appears that surplus rainfall (Rainfall>PET) during mid-June to August received and it can be harvested and use in high irrigation demand months.

- KEY WORDS : Rainfall, Probability analysis, Irrigation water requirement, Crop planning

- HOW TO CITE THIS PAPER : Vivekanand, Kumar, Vinod, Singh, Vijay Kumar and Singh, Bhaskar Pratap (2017). Weather parameter based crop planning in Tarai region of Uttarakhand. Internat. J. Agric. Engg., 10(2) : 360-366, DOI: 10.15740/HAS/IJAE/10.2/360-366. 